\title{
8
}
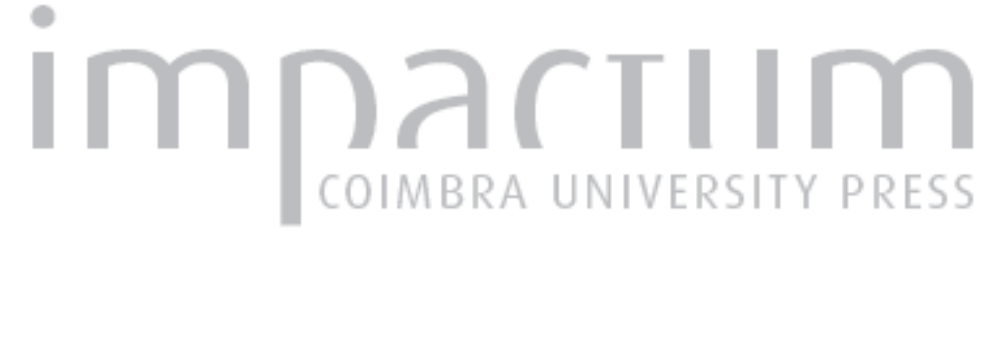

\section{Episódios hidrometeorológicos extermos noticiados no distrito de Coimbra durante a segunda metade do século XIX} \author{
Autor(es): $\quad \begin{aligned} & \text { Nunes, Adélia; Lourenço, Luciano; Pinho, João; Bento-Gonçalves, } \\ & \text { António; Vieira, António }\end{aligned}$ \\ Publicado por: Associação Portuguesa de Riscos, Prevenção e Segurança \\ URL \\ persistente: \\ URI:http://hdl.handle.net/10316.2/35836 \\ DOI: \\ DOI:http://dx.doi.org/10.14195/1647-7723_20_3 \\ Accessed : $\quad$ 26-Apr-2023 01:47:42
}

A navegação consulta e descarregamento dos títulos inseridos nas Bibliotecas Digitais UC Digitalis, UC Pombalina e UC Impactum, pressupõem a aceitação plena e sem reservas dos Termos e Condições de Uso destas Bibliotecas Digitais, disponíveis em https://digitalis.uc.pt/pt-pt/termos.

Conforme exposto nos referidos Termos e Condições de Uso, o descarregamento de títulos de acesso restrito requer uma licença válida de autorização devendo o utilizador aceder ao(s) documento(s) a partir de um endereço de IP da instituição detentora da supramencionada licença.

Ao utilizador é apenas permitido o descarregamento para uso pessoal, pelo que o emprego do(s) título(s) descarregado(s) para outro fim, designadamente comercial, carece de autorização do respetivo autor ou editor da obra.

Na medida em que todas as obras da UC Digitalis se encontram protegidas pelo Código do Direito de Autor e Direitos Conexos e demais legislação aplicável, toda a cópia, parcial ou total, deste documento, nos casos em que é legalmente admitida, deverá conter ou fazer-se acompanhar por este aviso.

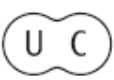




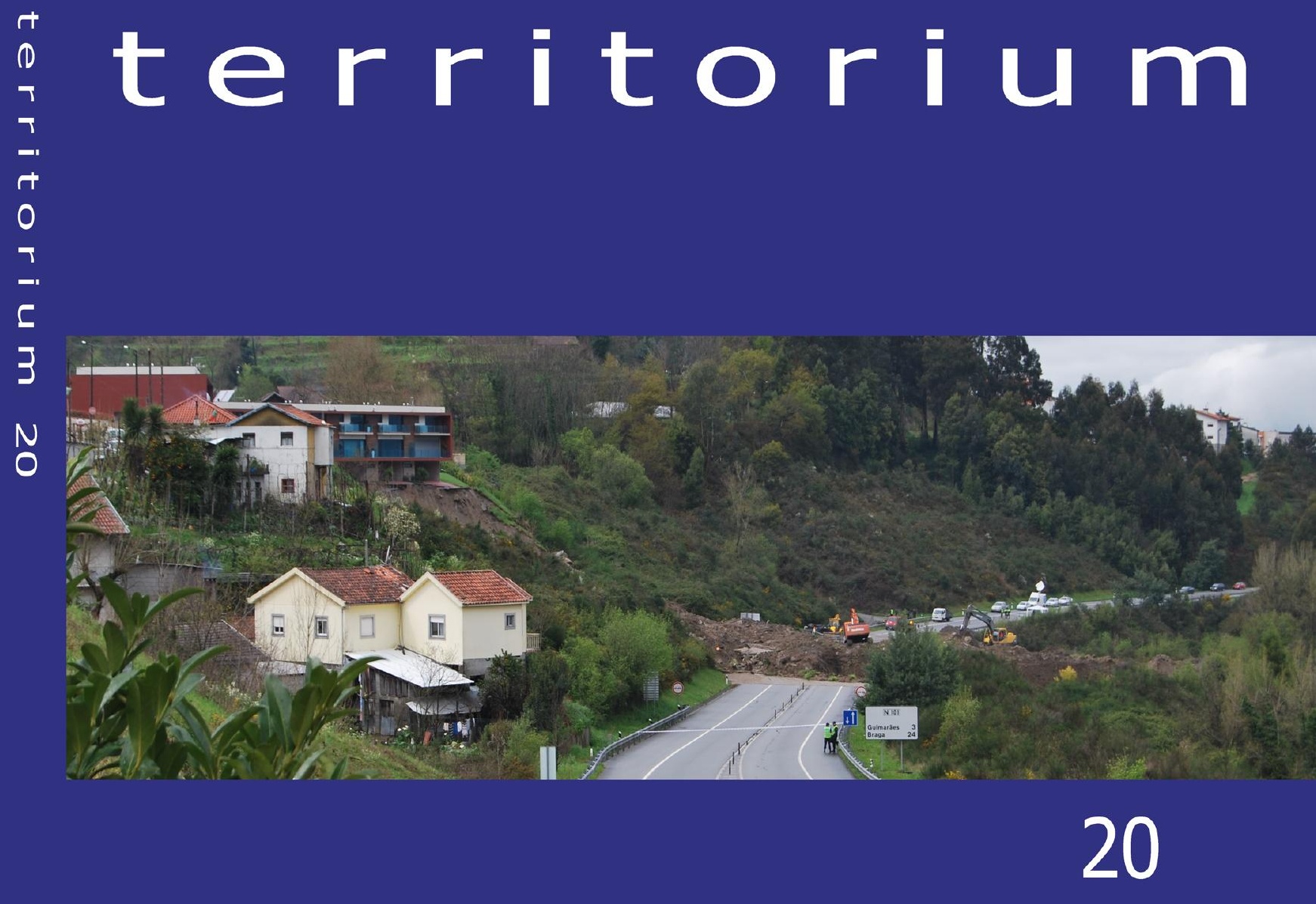

Riscos, População e Segurança 
territorium 20, 2013, 29-36

journal homepage: http://www.uc.pt/fluc/nicif/riscos/Territorium/numeros_publicados

EPISÓDIOS HIDROMETEOROLÓGICOS EXTREMOS NOTICIADOS NO DISTRITO DE COIMBRA DURANTE A SEGUNDA METADE DO SÉCULO XIX*

Departamento de Geografia, CEGOT, Faculdade de Letras da Universidade de Coimbra adelia.nunes@ci.uc.pt

Luciano Lourenço

Departamento de Geografia, CEGOT, Faculdade de Letras da Universidade de Coimbra

luciano@uc.pt

João Pinho

Investigador de História Local e Regional joaocspinho@gmail.com

António Bento-Gonçalves

Departamento de Geografia, CEGOT, Instituto de Ciências Sociais, Universidade do Minho bento@geografia.uminho.pt

António Vieira

Departamento de Geografia, CEGOT, Instituto de Ciências Sociais, Universidade do Minho vieira@geografia.uminho.pt

\section{RESUMO}

Identificar as áreas que sofreram eventos históricos constitui o primeiro passo para uma análise integral do risco. Com o presente trabalho pretende-se analisar a incidência espacial de episódios hidrometeorológicos extremos, no decurso da segunda metade do século XIX, no distrito de Coimbra. Para o efeito, recorreu-se aos jornais da época como fontes de informação fidedigna, uma vez que nesse período não existiam recolhas sistemáticas dos principais elementos do sistema hidroclimático.

Palavras chave: Risco histórico, episódios hidrometeorológicos extremos, distrito de Coimbra, Portugal.

\section{RESUMEN}

Episodios hidrometeorológicos extremos reportados en el distrito de Coimbra durante la segunda mitad del siglo XIX Identificar las áreas que han sufrido acontecimientos históricos es el primer paso hacia un análisis integral de riesgos. El presente trabajo tiene como objetivo analizar la distribución espacial de los episodios hidrometeorológicos extremos durante la segunda mitad del siglo XIX, en el distrito de Coimbra. Para ello, hemos utilizado los periódicos de la época como fuente de información fiable, ya que en eso tiempo no había recopilación sistemática de los elementos clave del sistema hidroclimático.

Palabras clave: Riesgo histórico, episodios hidrometeorológicos extremos, distrito de Coimbra, Portugal.

\section{RÉSUMÉ}

Épisodes hydrométéorologiques extrêmes rapportés dans le district de Coimbra au cours de la seconde moitié du XIXe siècle - Identifier les zones qui ont souffert des événements historiques est la première étape vers une analyse complète des risques. Le présent travail vise à analyser la distribution spatiale des épisodes extrêmes hydrométéorologiques au cours de la seconde moitié du XIXe siècle, dans le district de Coimbra. À cette fin, nous avons utilisé les journaux de l'époque comme des sources d'informations fiables, une fois que dans cette époque, il n'y avait pas de collecte systématique des éléments clé du système hydroclimatique.

Mots-clé: Risque historique, épisodes hydrométéorologiques extrêmes; district de Coimbra, Portugal.

\section{ABSTRACT}

Extreme Hydrometeorological episodes reported in the district of Coimbra during the second half of the 19th century Identify the areas that have suffered historical events is a first step towards a comprehensive risk analysis. The present work aims to analyze the spatial distribution of extreme hydrometeorological episodes during the second half of the nineteenth century, in the district of Coimbra. For that purpose, we resorted to the newspapers of the era as sources of reliable information, since this period there were no systematic collection of key elements of the hydroclimatic system.

Keywords: Historical risk, extreme hydrometeorological events, district of Coimbra, Portugal.

* O texto deste artigo corresponde à comunicação apresentada ao VII Encontro Nacional de Riscos e I Forum ISCIA, tendo sido submetido para revisão em 07-11-2012, e aceite para publicação em 12-11-2012.

Este artigo é parte integrante da Revista Territorium, n. ${ }^{\circ} 20,2013,{ }^{\circ}$ RIscos, ISBN: 0872- 8941. 


\section{Introdução}

Classificada como uma região de risco, a bacia do Mediterrâneo é um espaço geográfico exposto a vários riscos naturais com manifestação sobre os territórios, as populações e as atividades nele instaladas, interferindo, de forma conjuntural ou estrutural, no quotidiano destas sociedades. A irregularidade anual e inter-anual da precipitação é um fenómeno característico desta área, o que em associação com as características geomorfológicas, torna esta região uma área de risco muito elevado, recorrentemente atingida por catástrofes de origem hidrometeorológica (LouRENçO, 1999; Rebelo,2003; TAvares E Cunha, 2007; Olcina Cantos, 2010; Rebelo, 2010; Cunha, 2012).

A UNISDR (United Nations International Strategy for Disaster Reduction) (UNITED NATIONS, 2009) integra nos riscos hidrometeorológicos os ciclones tropicais (também conhecidos como tufões ou furacões), as tempestades, o granizo, os tornados, as avalanches, as tempestades costeiras, as inundações, as secas, as ondas de calor e as vagas de frio. Considera, ainda, que as condições hidrometeorológicas podem constituir fatores relevantes na manifestação de outros tipos de riscos, como por exemplo movimentos em massa, incêndios florestais, pragas, epidemias, e interferir no transporte e dispersão de substâncias tóxicas e materiais de erupção vulcânica.

De acordo com MAREngo et al. (2004) só é possível definir extremos hidrometeorológicos quando se pode determinar os seus impactos (perdas económicas, perdas de vidas, etc.) ou suas causas físicas (chuvas acima ou abaixo de determinado limiar durante um período de tempo, descargas de acima de um limiar definido). 0 reconhecimento, inventariação e caracterização de eventos hidrometeorológicos extremos (secas, excessos hídricos, tempestades ou outros), ocorridos num período anterior à instalação de quaisquer tipos de estações hidrometeorológicas, obriga à utilização de outras fontes indiretas, ou seja documentos produzidos com outras finalidades (AlCOFORADO, 2008), mas onde estes fenómenos se encontram datados e espacialmente referenciados.

De fato, para uma eficaz gestão da crise e do processo de tomada de decisão a ela associado, é necessário conhecer suficientemente o risco. Identificar as áreas que sofreram eventos históricos constitui o primeiro passo para uma análise de risco, pois permita identificar potenciais áreas de manifestação. Do mesmo modo que o estudo dessas manifestações, no passado, pode ajudar a prever a magnitude das que, eventualmente, venham a manifestar-se no futuro.

Com o presente trabalho pretende-se analisar a incidência espacial de episódios hidrometeorológicos extremos, no decurso da segunda metade do século XIX, no distrito de Coimbra. Para o efeito, recorreu-se aos jornais da época e a outros documentos históricos como fontes de informação fidedigna, uma vez que nesse período não existiam recolhas sistemáticas dos principais elementos do sistema hidroclimático. Esta análise permite, também, problematizar a exposição e a vulnerabilidade da sociedade, na época em análise, bem como as consequências da manifestação desses riscos.

\section{Área de Estudo}

A área de estudo abrange o distrito de Coimbra, constituído por 17 municípios (fig. 1), com uma área de cerca de $4000 \mathrm{~km}^{2}$. 0 rio Mondego e seus afluentes são elementos estruturantes deste território, enquadrado em duas grandes unidades morfoestruturais: a metade oriental, no Maciço Hespérico e, a metade ocidental, na Orla Mesocenozóica ocidental. É no limite oriental do distrito que se assinalam os relevos de maior altitude, coincidindo com as vertentes ocidentais das serras do Açor e da Lousã. Entre estas serras, do bloco ocidental da Cordilheira central, e as do Maciço marginal de Coimbra, estende-se uma área relativamente plana, onde se encaixam algumas depressões, como a de CojaArganil e da Lousã.

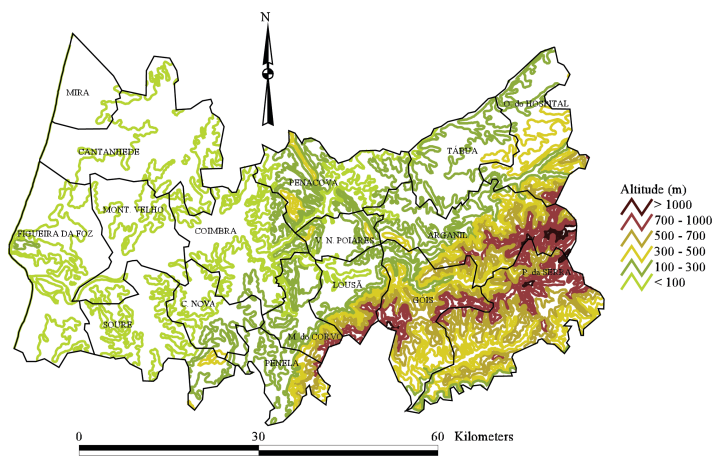

Fig. 1 - Área de estudo e respetiva variação altimétrica. Fonte: Atlas do Ambiente, altimetria.

A oeste do Maciço Marginal de Coimbra as altitudes são pouco relevantes, ultrapassando localmente, os $300 \mathrm{~m}$. A estes contrastes hipsométricos associam-se gradientes pluviométricos bastante relevantes, a oscilar entre os 700 e os $2000 \mathrm{~mm}$ de precipitação média anual (fig. 2). O regime pluviométrico, com características mediterrâneas, define-se, por um semestre chuvoso (de Outubro a Março), com cerca de $70 \%$ da precipitação média anual, que coincide com a estação fria, e um semestre seco coincidente com estação quente.

Com refere F. BRAUdel, nas suas memórias sobre o mediterrâneo "cremos demasiado na suavidade, na facilidade espontânea da vida mediterrânea. É deixar-se enganar pelo encanto da paisagem. A terra cultivável é escassa (...) a água das chuvas está mal repartida: abunda quando a vegetação descansa no inverno, desaparece quando mais dela necessitam as plantas nascestes...". Acrescenta ainda que "no Mediterrâneo, a chuva pode 


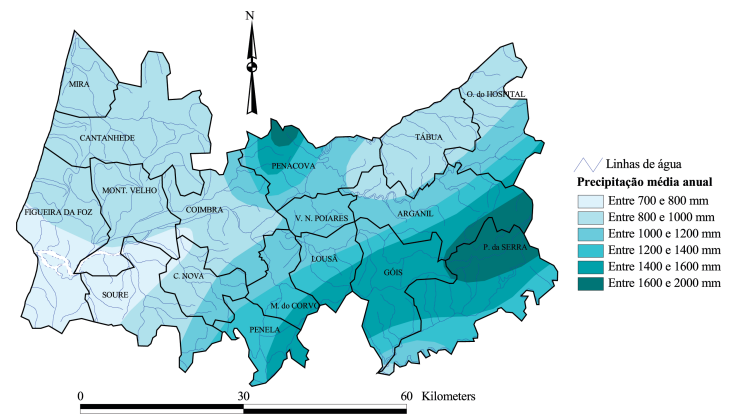

Fig. 2 - Variação espacial da precipitação média anual. Fonte: Atlas do Ambiente, Precipitação Média Anual (1931-60), 1974.

chegar demasiado abundante ou insuficiente, os ventos caprichosos podem trazer, num momento inoportuno, a seca ou o excesso de água...".

\section{Metodologia}

Para a análise da incidência espacial de episódios hidrometeorológicos extremos, no decurso da segunda metade do século XIX, recorreu-se aos jornais da época como fontes de informação fidedigna, uma vez que nesse período não existiam recolhas sistemáticas dos principais elementos do sistema hidroclimático. Os jornais fornecem alguma da mais importante informação documental descritiva, uma vez que descrevem o evento, as causas, os impactes, sendo que em muitas ocasiões se referem com detalhe aos danos causados pela sua manifestação. Todavia, para que possam ser utilizados como fontes documentais fidedignas deverão obedecer a alguns requisitos, entre os quais se salientam:

(I) continuidade temporal (Le Roy LadurIE, 1967);

(II) homogeneidade e datação exata dos factos, ou seja deverão ser contemporâneos dos fenómenos descritos (AleXANDRe, 1987).

Os jornais "O Observador", com publicação bi-semanal, entre 1850 e 1854, a que sucedeu o "Conimbricense", entre 1854 e 1908, permitiram uma recolha sistemática de notícias relativas a eventos hidrometeorológicos extremos no distrito de Coimbra, tendo sido identificados os seguintes fenómenos:

- Secas, referenciadas através da realização de Procissões de preces pela Venerável Ordem Terceira (VOT). Com estas cerimónias, que ocorriam em períodos de calamidade para as comunidades, pretendiam obterse benesses divinas e "aplacar a ira divina de Deus", auxiliando na resolução desses problemas.

- Cheias e inundações no Mondego, cuja descrição das perdas humanas ou dos avultados danos materiais era detalhada.

- Trovoadas, igualmente referenciadas através da descrição das perdas humanas ou dos avultados danos materiais, por elas desencadeadas.
Assume-se, assim, que os eventos hidrometeorológicos que reúnem as condições mencionadas terão sido suficientemente relevantes para serem relatados pelos órgãos de comunicação social da época.

\section{Resultados}

Episódios de secas

No decurso da segunda metade do século XIX, os jornais consultados fizeram referência à realização de procissões de preces, por parte da VOT, em 7 anos, 3 dos quais na década de 50 (nos anos de 1851, 1854 e 1859) (fig. 3). Em 1851, 1854 e, também, em 1868 verificou-se a repetição de preces devido ao prolongamento e à intensificação destes episódios. Apesar deste tipo de rogatória poder ocorrer em qualquer mês do ano, parece ter sido nos meses de inverno e de primavera que se assinalam o maior número.

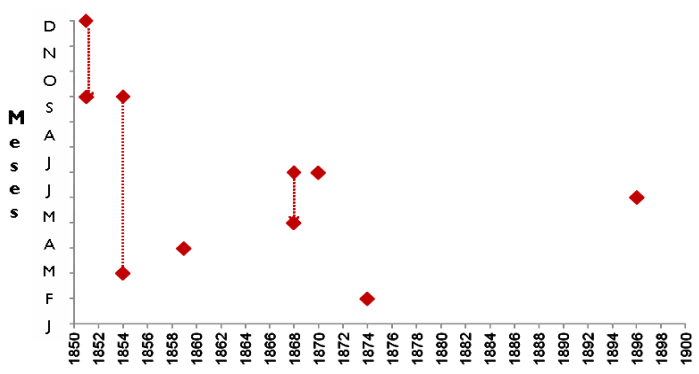

Fig. 3 - Evolução anual e distribuição mensal dos episódios de secas, entre 1850-1900. Fonte: Elaboração própria a partir dos dados recolhidos nos jornais "O Observador" e o "Conimbricense".

A propósito da seca de 1851 refere o jornal que, em meados de Setembro, a VOT da Penitência "começara na quinta feira a fazer preces na sua Igreja do Carmo e que terminarão na sexta feira da próxima semana". Preces ao Altíssimo, para que afastasse do reino e, principalmente, desta cidade a lamentável calamidade pública do excessivo calor e prolongado estio, para que chovesse pois a "quadra que vai decorrendo, além de excessivamente calmosa, tem sido muitíssimo seca. A falta de chuvas que há tanto tempo se sofre, tem feito minguar as águas do Mondego, a ponto tal, que este rio, que tão caudaloso e soberbo é no inverno, está agora reduzido a insignificantes regatos disseminados num extenso e ávido areal. A navegação está tão difícil, que um barco, mesmo levemente carregado, gasta um dia para chegar a Pereira ou Formoselha, duas léguas ou três desta cidade".

Todavia, as preces não terão sido suficientes para colmatar a escassez de água que, desde há vários meses, se faziam sentir pois em meados do mês de Dezembro, o mesmo jornal dava conta de preces feitas na cidade devido à "falta de chuva que se tem prolongado por tanto tempo (...) causando graves transtornos. Os verdes estão definhados; a palha de milho tem tido muito consumo 
no sustento dos gados, o que deve causar carestia de alimentos para a estabulação no inverno. Muitas fontes, cisternas e nascentes tem secado. Quintas, onde nunca houve falta de água, abastecem-se agora da água do rio. Muitos lagares moem a azeitona movidos por bois. o Mondego espreguiça-se mansamente no seu leito de areias, tão pobre e minguado como no estio".

De facto, no passado tal como no presente, a ausência prolongada de chuvas, em qualquer época do ano causava "grandes prejuisos a todas as classes da sociedade, destruindo os géneros de primeira necessidade» $e$ ameaçando com "maiores flagellos" (18 de Abril de 1868). Aliás, o jornal decide recordar as procissões de penitência feitas pela OT "...nas grandes seccas, que no século passado houve nos annos de 1738, 1744, $1753 e$ 1793". A propósito da seca de 1737, conta o jornal que "havia decorrido o inverno sem chover; a terra estava secca e dura; os gados sem pastos, e as sementeiras sem se poderem effectuar. Em todo o Portugal se tinham feito preces; e por fim resolveu a cidade de Coimbra fazer uma solemne procissão, para deprecar o favor divino (...). A procissão saiu da Igreja de Santa Cruz no dia 26/2, dia de S. Matias, pelas 6 horas. Deu voltas pelo bairro baixo e bairro alto. 0 Acto religioso durou 6 horas e terminou com um sermão pregado no claustro pelo missionário Varatojo(...). Ouviu Deus os rogos dos fieis; porque no dia seguinte começou a chover".

No mencionado ano de 1744 , refere que "houve neste reino, em razão dos grandes calores, uma quasi total esterilidade, faltando o sustento a todos os viventes. Por causa disso fizeram-se preces nos mosteiros, conventos, collegiadas, recolhimentos, e mais egrejas e capellas".

Em 1753, o jornal mencionava que "houve uma grande esterilidade por falta de aguas. Seccaram quasi todas as fontes, não havia agua para os engenhos de moer, e os de azeite se tinham supprido á força de braços. Não havia farinhas, e em varias terras muitos gados morreram à sede. No principio do mez de Julho, o nosso rio Mondego levava pouco mais de duas varas de medir panno de largura e dois palmos de altura. No dia 8 do dito mez, que era domingo, principiaram as preces pela irmandade da Ordem Terceira, na sua capella de S. Francisco da Ponte (...). Na quarta feira, 11 do mesmo mez de Julho, se fez a procissão de penitência, sahindo da capella de S. Francisco em direcção á egreja de Santa Cruz (...). O andor foi collocado na capella mor, aonde esteve até sexta feira da semana seguinte, 20 do mesmo mez. No dito dia 20 de Julho, de noute, por serem acabados os nove dias de preces na egreja do mosteiro de Santa Cruz, e ainda não ter chovido; voltou o andor em procissão para a capella de S. Francisco da Ponte, mas sem o Santo Lenho, pallio, nem tochas (...). Continuou ainda o tempo secco até sexta feira seguinte, 27 de Julho, em que cahiu alguma chuva".
Episódios de cheias e inundações

No decorrer da segunda metade do séc. XIX foram identificados 15 episódios de cheias e inundações, com graves prejuízos na cidade de Coimbra, demostrando a regularidade com que as áreas mais baixas da urbe eram afetadas (fig. 4). Além dos enormes prejuízos materiais que estes eventos desencadeavam, também em muitas ocasiões se referiam vítimas mortais. Exemplo disso são as cheias que ocorreram no final do ano de 1860 que, como refere o jornal, terão atingido diferentes magnitudes, sendo referido um primeiro evento, o qual era comparado a um outro que tinha ocorrido em 1852, mas um outro pico de cheia, mais intenso, ter-se-á registado na sequência, daquilo que nos é possível inferir a partir da seguinte descrição "...a cheia de segunda-feira tinha igualado a de 1852, mas em aquella noute as aguas tomaram uma altura verdadeiramente assustadora, excedendo a do principio da semana em mais de palmo e meio. O terror tinha-se apoderado de todas as famílias; e muita gente do bairro baixo sahiu de suas casas (...) São inumeráveis os prejuízos causados pela cheia, e o que é mais para lamentar, desta vez a inundação fez victimas! Pela uma hora da noute desabaram umas casas no beco do Bacalhau. Moravam n'ellas 9 pessoas. Destas falleceram 5, que foram, homem, mulher, um filho, $e$ duas crianças que tinham a criar". Aliás esta cheia, e a inundação por ela provocada, terá sido uma das mais intensas pois "chegou a cubrir o principio dos passeios da Rua da Sophia, e a passar na Praça entre a rua das Azeiteiras e a rua das Solas, o que nunca se havia presenceado em Coimbra".

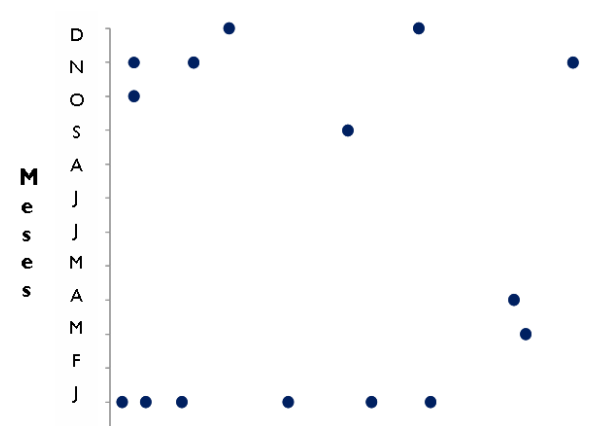

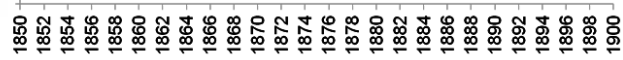

Fig. 4 - Evolução anual e distribuição mensal dos episódios de cheias e inundações no rio Mondego, em Coimbra, entre 18501900. Fonte: Elaboração própria a partir dos dados recolhidos nos jornais "O Observador" e o "Conimbricense".

Os fatores desencadeantes desta cheia no Mondego terão ocasionado, igualmente, cheias em outras linhas de água, referindo-se o jornal que na "freguezia de Botão, deste concelho, foram destruídas todas as pontes, açudes, e muitas azenhas. Unicamente escapou a ponte do cimo da villa, por se ter coberto de materiaes que o ribeiro arrojou sobre ella. Não há recordação de haver alli uma cheia igual". Acrescenta, ainda, que "proximo 
dos Fornos a força das aguas destruiu o pontão, e cortou a estrada transversalmente, e só a muito custo é que se pode restabelecer a comunicação".

A análise à distribuição mensal, mostras que Dezembro e Janeiro foram os que assinalaram maior número de eventos, sendo destacar uma cheia em Setembro e duas em Março/Abril. No mês de Setembro, no dia 20, davam conta de o Mondego se ter enchido rapidamente na véspera, pelas 6 horas da tarde "...achando-se o alveo do Mondego quasi todo coberto de areia, principiou repentinamente a encher-se com tal rapidez e volume de aguas, que poucas horas depois se elevava o rio à altura de uma grande cheia, occupando todo o espaço dos arcos da ponte", atribuindo o facto "a alguma extraordinária trovoada que desconheciam onde caísse".

\section{Episódios de trovoadas}

A trovoada constitui um dos mais dramáticos fenómenos meteorológicos, uma vez que tem associado raios que são portadores de enormes quantidades de energia electromagnética e precipitação frequentemente intensa. A trovoada é um fenómeno meteorológico que ocorre em Portugal associado principalmente à aproximação e passagem de superfícies frontais frias e à ascensão de massas de ar muito húmido resultante de movimentos convectivos que ocorrem por efeito orográfico ou sobre as superfícies terrestres aquecidas pela intensa radiação solar.

No período em análise (fig. 5), assinalaram-se mais de meia centena de eventos, cujos prejuízos materiais e/ou a ocorrência de vitimas humanas motivou a sua divulgação na imprensa da época. A análise da distribuição anual mostra que os anos de 1861 e 1900 foram os que mais eventos assinalaram, 12 e 10 trovoadas respetivamente. A sua distribuição intraanual denuncia a existência de uma maior concentração destes episódios nos meses de Julho e Outubro, com um total de 12 ocorrências, seguidos de Maio e Junho, com 8 eventos cada um. Curiosamente, durante os meses de Inverno não foram reportadas danos causados pela ocorrência de trovoadas ao passo que nos meses de verão se registaram $50 \%$ das manifestações.

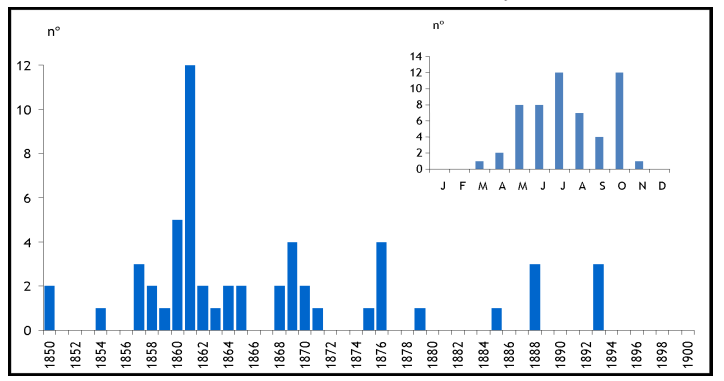

Fig. 5 - Evolução anual e distribuição mensal dos episódios de trovoada, entre 1850-1900.

Fonte: Elaboração própria a partir dos dados recolhidos nos jornais "O Observador" e o "Conimbricense".
As descargas elétricas, associadas a trovoada, são manifestações extremas da instabilidade atmosférica e um dos fenómenos meteorológicos mais devastadores, pois condicionam o funcionamento de numerosas atividades sócio-económicas e podem até causar a perda de vidas humanas. São inúmeras as descrições da violência destes fenómenos e dos danos por eles causados, nomeadamente no que se refere à perda de vidas humanas e também de animais. Com efeito, numa época marcada pela inexistência de para-raios e em que a maioria da população se dedicava às atividades agrícolas, passando grande parte do dia no campo, as vítimas mortais de descargas elétricas eram frequentes, tendo sido, nos 50 anos analisados, identificadas 16 vítimas.

A incidência espacial dos episódios de trovoada, entre 1850 e 1900 , coloca em destaque o concelho da Pampilhosa com 9 ocorrências, sendo quase sempre dramáticas as descrições das consequências da sua manifestação, pela violência que estes fenómenos podem ocasionar nas áreas onde se abatem (fig. 6).

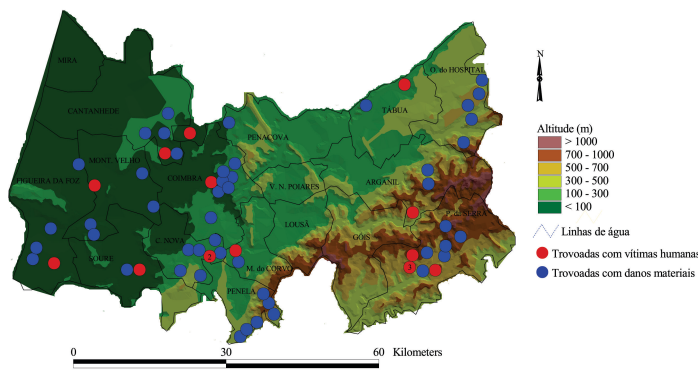

Fig. 6 - Incidência espacial dos episódios de trovoada, entre 1850 e 1900, por concelho e classes de hipsometria.

Fonte: Elaboração própria a partir dos dados recolhidos nos jornais "O Observador" e o "Conimbricense".

São disso exemplo os relatos que se seguem. 0 primeiro refere-se a uma trovada que ocorreu em meados de Setembro de 1854, cuja descrição se faz no jornal do dia 20 do mesmo mês: "Pelas 2 horas da tarde, no concelho da Pampilhosa, principiou uma tão forte trovoada, que parecia arrazar tudo. As grandes torrentes levavam diante de si as paredes, terra, e tudo quanto encontravam. Muitas famílias ficaram reduzidas à ultima miséria, porque a trovoada não só lhes levou os fructos pendentes, mas lhes arruinou inteiramente as propriedades. Alguns gados se afogaram nos curraes, e outros marcharam com a corrente. Muitas das pedras que cahíram, eram do tamanho de ovos de perdiz. 0 quadro que offerecia todo o concelho depois que cessou a trovoada, era desanimador. Era triste scena o presencear os lamentos daquelles que tres horas antes se diziam remediados, e que estavam agora no estado mais desgraçado, e muitos delles obrigados a mendigar...". Em 1864, o jornal do dia 30 de junho dando conta das trovoadas ocorridas nos dias 23 e 24 de Junho, referia que "Na povoação de Janeiro de Baixo, de 20 moinhos que existiam em dois ribeiros que desaguam no Zêzere só ficaram 2; foram destruídos ainda 2 lagares e 
muitas terras. No lugar do Machalinho um raio fulminou um pastor e 19 cabeças de gado...".

Uma outra carta de Pampilhosa da Serra, de 18 de Junho de 1865, assinada por Pinheiro Feteira, referia que "Têem estes dias sido dias de terror e calamidade para os povos da Pampilhosa. Refiro-me aos medonhos estampidos $e$ terriveis effeitos das trovoadas, que têem e continuam a grassar por estes sítios. O dia 10 do corrente mez será lembrado entre nós, tendo uns a lamentar as grandes ruínas, que soffreram nas suas propriedades, não podendo outros ser insensíveis ás desgraças dos seus vizinhos. No dia 16, porém, subiram de ponto as desgraças, pois houve victimas a lamentar. Em uma serra, que pela parte do sul está imminente a esta villa, foram fulminados tres homens, d'uns povos visinhos, chamados as Aldeias, na occasião, em que, debaixo dum guarda chuva, pretendiam resguardar-se dos rigores da tempestade».(...) Hontem, próximo a outro lugar d'este concelho, Malhadas da Serra, ficou, em consequência de causa análoga, mui maltratada uma pastora, morreu outra, e dizem que o mesmo succedera a mais de 40 ovelhas de tres rebanhos, que aquellas andavam apascentando. (...) Ainda algumas das propriedades, que em 1858 foram estragadas, não tinham sido concertadas, ainda outras davam producções rachiticas e enfesadas, eis de novo muitas d'estas e outras destruídas pelos malignos effeitos das procellosas alluviões".

No concelho de Penela, nas freguesias de Espinhal e Cumieira, são igualmente recorrentes os relatos de ocorrência de trovoadas destacando a título de exemplo, uma carta dirigida do Espinhal, com data do dia 21 de maio de 1876, referindo "Que na sexta feira de tarde (...) uma grande trovoada descarregou sobre a Guia do Avelar e Venda dos Moinhos, onde não ficou nem um bocado de terra (...). Morreram uns poucos de rebanhos de gado, porcos e bois; e arrazaram-se casas pelos alicerses (...). A agua vinha toda junta, e fazia ondas como no mar (...). Era um dilúvio. Nós fugimos para um monte, $e$ outros para as vinhas". Da Cumieira, com data de 31 de Maio de 1864 também chega a notícia de que "Na terça feira, 24 do corrente, houve na freguezia da Cumieira, concelho de Penella, uma trovoada, que causou alli grandes estragos. No lugar da Venda dos Moinhos, foram completamente arrazadas duas casas, e um moinho de 4 pedras. Os donos das casas perderam tudo quanto nellas tinham. Foram levadas pela inundação 63 ovelhas, e tres carros. Calculam-se os prejuízos em mais de 80 contos de reis. A freguezia da Cumieira, do concelho de Penella, é infeliz com as trovoadas. A grande trovoada de 16 de Outubro de 1861, causou alli os avultados estragos, de que nessa epoca demos noticia ....".

No concelho de Coimbra, algumas das trovadas noticiadas, pelos danos causados ocorreram nas freguesias de Botão, Eiras, S. Paulo de Frades e Sto. António dos Olivais. A título de exemplo, relata-se o sucedido na freguesia de S. Paulo "na terça feira houvera alli uma forte trovoada, acompanhada de uma quantidade extraordinária de pedra, que cahiu com muita violência durante tres quartos de hora. Os prejuízos que causou são muito grandes. O milho ficou destruído; a azeitona cahiu em grande parte, e tambem soffreram muito as vinhas. Foi incalculável a pedra que cahiu, e de tamanho nunca visto naquella freguezia pelos homens mais antigos".

Uma outra trovoada, com elevados danos materiais, avaliar pela descrição de sucessivas notícias no jornal terá ocorrido Oliveira do Hospital, transcrevendo-se parte da carta enviada no dia 22 de junho de 1859 "No dia 18 de Junho corrente cahiu uma fortíssima trovoada nas povoações de Lagos, S. Paio de Gramaços, e outras circumvisinhas. A queda de muitas grossas pedras por mais de duas horas e meia fez destruir todos os fructos pendentes, como centeios, trigos, batatas e hortas. Desappareceram os cachos das videiras, e não ficou alli uma verdura. Os milhos sachados e por sachar foram também destruídos pela grande abundância d'aguas. Seguindo as aguas o seu curso levaram ao rio Cobral o enchente maior de que há noticia, e mesmo muito superior, ao que aqui houve em 18 de Maio de 1857. As regadas das duas margens do Cobral, no limite da freguezia de Lagares, e parte da de Travanca, foram muito destruídas, e bem assim alguns engenhos de moer farinha, azeite, açudes e fontes". Continua, referindo que "em Lagares cahiram essas desgraças em proprietários, e em Lagos, S. Paio, Nogueirinha, Gramaços e Bobadella em todas as pessoas. Estes povos acham-se reduzidos á miséria e sem meios de subsistir, porque tendo semeado as suas terras, não teem com que as semear de novo. Por isso a Camara Municipal se reuniu no dia 20 e nomeou comissões para se arranjarem as sementes a estes povos $e$ se lhes prestarem os mais urgentes soccorros, dando-se de tudo conhecimento ao Governador Civil do Districto".

\section{Conclusão}

A reconstituição histórica da manifestação de episódios hidrometeorológicos extremos, da sua incidência espacial e dos respetivos impactes contribui para a compreensão do passado e pode constituir informação privilegiada na gestão do território, no presente e no futuro. Por outro lado, o reconhecimento, inventariação e caracterização de eventos hidrometeorológicos extremos ocorridos no passado, revela-se de particular importância no contexto da atual discussão em torno das alterações do sistema hidroclimático e dos seus efeitos a nível regional.

A análise à $2^{\mathrm{a}}$ metade do século XIX mostra a susceptibilidade e a vulnerabilidade da área de estudo à manifestação de fenómenos hidrometeorológicos extremos. Os episódios de seca, que motivavam o apelo 
ao divino, ocorriam, tendo por base as descrições dos jornais, quando os vários sectores que necessitam de água já se deparavam com a sua escassez. 0 défice de precipitação afetava o sector agrícola (seca agrícola), mas também a disponibilidade de recursos hídricos superficiais e subsuperficiais (seca hidrológica), com consequências socioeconómicas verdadeiramente nefastas, numa época em que os mecanismos de gestão de recurso hídricos era escassa.

As copiosas chuvas que caiem anualmente no maciço central e a fusão de neves acumuladas nas serras foram os principais fatores responsáveis pela ocorrência histórica de cheias no Mondego, que inundavam recorrentemente a parte baixa da cidade e o campos da sua planície aluvial. Com refere Rebelo (2010), ao longo dos tempos históricos foram muitas as crises a gerir nos campos do Mondego. Com efeito, o problema do assoreamento do Baixo Mondego, secularmente agravado pela destruição do coberto vegetal, por corte de árvores, ou por incêndios florestais é bem conhecido e encontra-se documentado em Martins (1940), LouREnço (2009) ou Rebelo (2010). Aliás, o problema das cheias e inundações do baixo Mondego ficou minimizado, não resolvido, com o Plano de regularização do Mondego, como comprovaram as cheias ocorridas no inverno de 2000/01 (PROENÇA, 2002; Rebelo, 2010)

Um outro aspeto a destacar, prende-se com a forte incidência de trovoadas, com efeitos altamente devastadores em alguns dos municípios, tais como Pampilhosa, Penela (Cumieira e Espinhal) e Coimbra. 0 relevo vigoroso das serras da Cordilheira Central, com as suas encostas muito declivosas voltadas a NW, assim como os declives acentuados das vertentes do "Maciço Marginal de Coimbra", são áreas mais pluviosas e onde a fisiografia influencia negativamente a infiltração, promovendo o escoamento à superfície e a ocorrência de inundações e enxurradas na sequência de elevados quantitativos de precipitação, num curto espaço de tempo.

Todavia, a sua dispersão pelo território parece mostrar que estes fenómenos não dependem exclusivamente da inter-relação destes fatores (relevo e precipitação), pois no passado, tal como no presente, estes fenómenos, não são regulares nem do ponto de vista espacial nem temporal (Fig. 6). De fato, na explicação dos fatores desencadeantes e condicionantes encontrar-se-ão os elevados quantitativos de precipitação, mas igualmente outros fatores associados, sobretudo, ao uso e coberto vegetal. Num período em que a pressão das atividades agro-silvo-pastoris sobre o território era intensa, pelo predomínio, quase exclusivo, das atividades primárias, o potencial erosivo da água sobre o solo, cultivado ou com um escasso coberto vegetal, era mais enérgico, desencadeando situações, por vezes, desastrosas nos lugares onde as fortes chuvadas se abatiam.
Assim, é de enorme pertinência, no futuro, dar continuidade à investigação destes episódios extremos (no período anterior mas também posterior à criação da rede organizada de estações hidrometeorológicas) no intuito melhorar o conhecimento, quer da sua frequência e intensidade, duração e extensão espacial, assim como dos respetivos danos ocasionados.

\section{Referências bibliográficas}

Alcoforado, M. J. (2008) - “Fontes instrumentais e documentais para reconhecimento do clima do passado debatidos em conferência internacional”, Finisterra, Lisboa, ${ }^{\circ}$ XLIII, 86, p.157-159.

Alexandre, P. (1987) - Le climat en Europe au moyen âge. Ecole des Hautes Etudes en Sciences Sociales, Paris.

Cunha, L. (2012) - "Riscos climáticos no Centro de Portugal. Uma leitura geográfica". Revista Geonorte, Edição Especial, Manaus, V.4, N.4, p. $105-115$.

Cunha, P. P. (2002) - "Vulnerabilidade e risco resultante da ocupação de uma planície aluvial - o exemplo das cheias do rio Mondego (Portugal central) no Inverno de 2000/2001". Territorium, n 9 , p. 13-35.

Le Roy Ladurie, E. (1967) - Histoire du climat depuis l'an mil. Paris, Flammarion.

LOUREnçO, L. (1999) - "Coimbra e os riscos naturais. Passado e presente". Cadernos de Geografia e Actas do $1^{\circ}$ Colóquio de Geografia de Coimbra, Coimbra, $\mathrm{n}^{\circ}$ especial, p. 37-43.

Lourenço, L. (2009) - “Plenas manifestações do risco de incêndio florestal em serras do Centro de Portugal. Efeitos erosivos subsequentes e reabilitações pontuais". Territorium, n. ${ }^{\circ} 16, \mathrm{p}$. $5-23$.

Marengo, J.A.; Menéndez, A; Guetter, A.; Hogue; T.; Mechoso, C.R. (2004) - "Caracterización y Evaluación de Métodos de Predicción de Eventos Extremos de Clima y de la Hidrología en la Cuenca del Plata". Componente 2a: definición del sistema de predicción hidroclimática. Tema 3: eventos hidrometeorológicos extremos. Informe final.

Martins, A. F. (1940) - O esforço do Homem na Bacia do Mondego. Ensaio geográfico. Coimbra, Edição de Autor, 299 p.

Olcina Cantos, J. (2010)- "Prevención de riesgos: cambio climático, sequías e Inundaciones”, Fundación Nueva Cultura del Agua, Panel Científico- 
-técnico de Seguimiento de la Política de Aguas, Convenio Universidad de SevillaMinisterio de Medio Ambiente, $41 \mathrm{p}$.

Rebelo, F. (2003). Riscos Naturais e Acção Antrópica. Estudos e Reflexões. $2^{\text {a }}$ Ed. Revista e aumentada, Imprensa da Universidade de Coimbra, Coimbra, 286p.

Rebelo, F. (2010). Geografia Física e Riscos Naturais, Imprensa da Universidade de Coimbra, Coimbra, 215 p.
Tavares, A.; Cunha, L. (2007)- "Riscos naturais e ordenamento do território. Espaços-risco e interfaces territoriais na região Centro". Atas do VI Congresso da Geografia Portuguesa, Lisboa, 17-20 de Outubro, $12 \mathrm{p}$.

UNISDR (United Nations International Strategy for Disaster Reduction) (UNITED NATIONS (2009) - “UNISDR Terminology on Disaster Risk Reduction". United Nations International Strategy for Disaster Reduction, Geneve, Switzerland. 